\title{
Does Seasonal Reproductive State Affect the Neuroendocrine Response of the Ewe to a Long-Day Pattern of Melatonin?
}

\author{
Celia J. I. Woodfill, ${ }^{1}$ Nancy L. Wayne, ${ }^{2}$ and Fred J. Karsch ${ }^{3}$ \\ Reproductive Sciences Program and Department of Physiology, University of Michigan, \\ Ann Arbor, Michigan 48109-0404
}

\begin{abstract}
This study examined whether or not the reproductive response of female sheep to photoperiod varies with seasonal reproductive state. The specific objective was to test the hypothesis that the reproductive response to a long-day pattern of melatonin varies with the reproductive state of the ewe. The response examined was the synchronization of reproductive neuroendocrine induction (rise in serum luteinizing hormone, or LH) following nocturnal infusion of melatonin into pinealectomized ewes for 35 consecutive nights. This infusion restored a pattern of circulating melatonin similar to that in pineal-intact ewes maintained in a long photoperiod (LD 16:8). The ewes had been pinealectomized and without melatonin replacement for 16-25 months prior to the study. They were in differing reproductive states at the start of the infusion, as their endogenous reproductive rhythm had become desynchronized among individuals and with respect to time of year. Noninfused pinealectomized ewes served as controls. Regardless of the reproductive state at the start of the 35-day infusion of the longday pattern of melatonin, all treated ewes exhibited the same reproductive neuroendocrine response after the infusion was ended. This consisted of a synchronized rise in LH some 6-8 weeks after the infusion was terminated, the maintenance of a high level of serum LH for some 15 weeks, and a subsequent precipitous fall in $\mathrm{LH}$ to a very low level. These results provide evidence that a long-day pattern of melatonin can synchronize reproductive neuroendocrine induction in the ewe, regardless of reproductive condition, and thus do not support the hypothesis that this response differs with seasonal reproductive state.
\end{abstract}

Key words circannual rhythm, photoperiod, photoperiodic history, photoperiodism, pineal gland, seasonal reproduction, sheep, luteinizing hormone

Many studies suggest that the response of photoperiodic seasonal breeders to a particular daylength depends upon "photoperiodic history," or the photoperiod experienced in the animal's past (quail-Robinson and Follett, 1982; voles-Horton, 1984; Lee and Zucker, 1988; Siberian hamsters-Hoffmann et al., 1986; Hoffmann and Illnerová, 1986; sheepRobinson and Karsch, 1987; Ebling et al., 1989; Syrian hamsters-Hastings et al., 1989). For example, we have found that exposure to the same experimental photoperiod can produce opposite reproductive responses (induction or inhibition) in female sheep, depending on whether the previous photoperiod was longer or shorter than the experimental photoperiod

1. Present address: R\&D/POP/R, Room 820, U.S. Agency for International Development, Washington, D.C. 20523-1819.

2. Present address: Department of Biology, Gilmer Hall, University of Virginia, Charlottesville, Virginia 22901.

3. To whom all correspondence should be addressed, at Reproductive Sciences Program, University of Michigan, 300 N. Ingalls Building, Room 1100, Ann Arbor, Michigan 48109-0404. 
(Robinson and Karsch, 1987). It is possible, however, that the reproductive response to a specific photoperiod varies with the reproductive state, particularly in species that exhibit circannual rhythms (various birds-Gwinner, 1986; rainbow trout-Duston and Bromage, 1988; sheep-Jackson et al., 1989). Thus, one limitation of our earlier study on photoperiodic history in sheep relates to the possible confounding effect of differing reproductive states at the time of exposure to the experimental photoperiod. It is difficult, therefore, to interpret those findings definitively in terms of photoperiodic history.

The present study addressed the question of whether or not the response of female sheep to a particular photoperiod differs with seasonal reproductive state. Specifically, we tested the hypothesis that the reproductive neuroendocrine response to a long-day pattern of melatonin varies with the reproductive state of the ewe. The study was performed on ewes that had been pinealectomized 16-25 months previously. Pinealectomized ewes are unable to generate a reproductive response to ambient photoperiod, and, with time after surgery, such ewes exhibit differing reproductive states as individuals express circannual rhythms that become desynchronized (Bittman et al., 1983b; Wayne et al., 1990; Woodfill et al., 1991). Such reproductively desynchronous ewes, therefore, provide an experimental model in which the influence of reproductive state can be evaluated in the absence of an influence of recent photoperiodic history.

In the present study, pinealectomized ewes in different reproductive states were challenged with nightly infusion of a long-day pattern of melatonin, and the ability of this treatment to synchronize the onset of reproductive activity was monitored. We predicted that if reproductive state affects the response of the ewe to a long-day pattern of melatonin, then ewes in different reproductive conditions should respond differently to this melatonin treatment. On the other hand, if this response does not depend on reproductive state, we predicted that all ewes receiving the long-day pattern of melatonin would respond similarly.

\section{MATERIALS AND METHODS}

\section{GENERAL}

The experiment was conducted over an 11-month period (July 1988-May 1989) on 18 adult purebred or predominantly Suffolk ewes maintained at the Sheep Research Facility near Ann Arbor, Michigan $\left(42^{\circ} 18^{\prime} \mathrm{N}\right)$. Initial ages were unknown, but ewes were sexually mature at the start of the study. Ewes were kept outdoors and were physically isolated by at least $90 \mathrm{~m}$ from rams and other ewes in a separate paddock, to minimize social influences on reproductive function. All ewes were maintained on fresh pasture supplemented with hay during periods of frost and snowcover (approximately 5 months), and they had free access to water and mineral licks.

The ewes were pinealectomized between June 1986 and March 1987, an average of 18 months (range 16-25 months) before the experiment (details in Wayne et al., 1990); a modification (Dempsey et al, 1982) of the procedure of Roche and Dziuk (1969) was used. Completeness of pinealectomy was assessed initially by examination of the excised pineal and its removal site, and confirmed later by the absence of a nighttime rise in circulating melatonin. Melatonin was infused intravenously into 12 of the 18 pinealectomized ewes at night by means of a backpack infusion system described in detail elsewhere (Bittman et al., 
1983a; Wayne et al., 1988; Woodfill et al., 1991). A cannula (inner diameter, $0.5 \mathrm{~mm}$; outer diameter, $1.5 \mathrm{~mm}$ ) was inserted into the jugular vein and attached to a pump (Autosyringe, AS-6MP, Hooksett, NH) programmable for time and dosage. The pump infused melatonin (Sigma) dissolved in physiological saline at a rate of $44 \mu \mathrm{g} / \mathrm{hr}$ for $8 \mathrm{hr}$ a night, thus simulating the melatonin pattern secreted by pineal-intact ewes on a long photoperiod (LD 16:8) (Woodfill, 1990).

Each ewe was ovariectomized at least 18 months before the study and treated from the time of ovariectomy with a subcutaneous Silastic capsule packed with $3.0 \mathrm{~cm}$ of crystalline estradiol-17 $\beta$ (Karsch et al., 1973). Just prior to the start of this study, a new estradiol capsule was inserted in place of the old one. The implants maintain a serum estradiol concentration $(\sim 3 \mathrm{pg} / \mathrm{ml})$ intermediate to that in the luteal and follicular phases of the estrous cycle (Legan et al., 1977). Seasonal reproductive condition was monitored by determining changes in serum luteinizing hormone ( $\mathrm{LH}$ ) concentrations, which reflect shifts in neuroendocrine response to the fixed negative feedback signal provided by the constant-release estradiol implant. In this model, LH secretion in pineal-intact ewes varies from high levels $(10-20$ $\mathrm{ng} / \mathrm{ml})$ in the breeding season to very low levels $(<0.5 \mathrm{ng} / \mathrm{ml})$ during anestrus (Legan et al., 1977; Karsch et al., 1989). This changing response to estradiol negative feedback constitutes a primary neuroendocrine determinant of seasonal reproductive state (Karsch et al., 1984; Legan and Karsch, 1979).

\section{EXPERIMENTAL DESIGN}

Figure 1 illustrates the experimental design. Of the 18 pinealectomized ewes, 12 were infused with the long-day pattern of melatonin; the remaining 6 ewes served as noninfused controls (saline vehicle not infused because this does not affect reproductive state; Wayne et al., 1988). The infusion lasted 35 days (October 21 -November 25, 1988), as previous work indicates that 35 days of a long-day signal can evoke photoperiodic responses in female sheep (Foster et al., 1988; Jackson et al., 1988). At the start of the infusion, ewes were in different reproductive states, because pinealectomy 16-25 months earlier had disrupted the photoperiodic response and caused the circannual rhythm to become desynchronized. Of the 12 experimental ewes, 4 were reproductively suppressed (low LH), 2 were in the transition

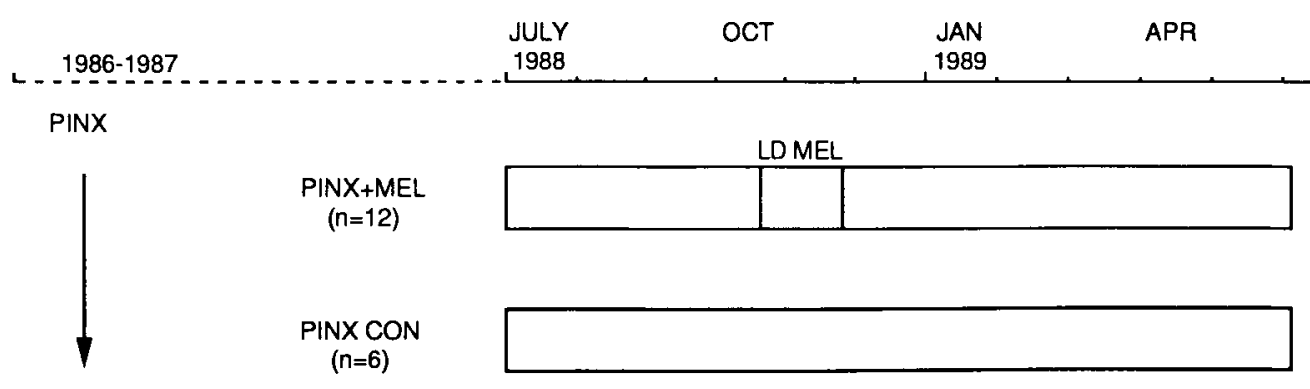

FIgURE 1. Experimental design to test importance of reproductive state on photoperiodic response. Horizontal bars show time of experiment, with shading indicating 35 days of infusion of the long-day pattern of melatonin (LD MEL). Ewes were pinealectomized (PINX) between June 1986 and March 1987, and were either treated with melatonin 16-25 months later (PINX + MEL) or not infused (PINX CON). Number of animals is indicated by $n$. 
between inactivity and activity ( $\mathrm{LH}$ rising), and 6 were reproductively active (high $\mathrm{LH}$ ). Of the 6 noninfused controls, 4 ewes were reproductively active and 2 were inactive when the infusion started in the experimental ewes. Circulating LH was monitored for a period of 11 months, beginning approximately 3.5 months before the start of the melatonin infusion.

Radioimmunoassay of melatonin verified that the infusion maintained a 24-hr pattern of circulating melatonin comparable to that in pineal-intact ewes on a long photoperiod (LD 16:8). Serum levels of melatonin during nights of infusion $(362 \pm 19 \mathrm{pg} / \mathrm{ml}$ ) were not different from the nighttime levels we observed in a group of pineal-intact ewes $(355 \pm 68$ $\mathrm{pg} / \mathrm{ml}$; Woodfill, 1990).

\section{SAMPLING AND ASSAYS}

Blood $(5 \mathrm{ml})$ was sampled by jugular venipuncture twice a week for assay of $\mathrm{LH}$. Blood for assay of melatonin was sampled every $2-4 \mathrm{hr}$ for $24 \mathrm{hr}$ on one occasion during the infusion to verify proper delivery, and at least once before the experiment to verify completeness of pinealectomy. Serum was obtained, processed, and stored as described elsewhere (Karsch and Foster, 1975). LH was determined in duplicate aliquots $(25-200 \mu \mathrm{l})$ of serum with a modification (Hauger et al., 1977) of the radioimmunoassay of Niswender et al. (1968, 1969). Values are expressed in terms of a reference preparation supplied by the National Institutes of Health (NIH-LH-S12). The limit of detection (two standard deviations from buffer control) averaged $0.43 \mathrm{ng} / \mathrm{ml}$. The intraassay coefficient of variation (CV) for three serum pools averaged $8.9 \%$; interassay $\mathrm{CV}$ for these pools averaged $11.0 \%$. Melatonin was measured in duplicate $200-\mu \mathrm{l}$ aliquots of unextracted serum; a modification (Malpaux et al., 1987) of the radioimmunoassay of English et al. (1986) was used. The limit of detection of the melatonin assay averaged $8.0 \mathrm{pg} / \mathrm{ml}$. The intra- and interassay CVs for 3 standard sera averaged $7.0 \%$ and $13.4 \%$, respectively.

\section{DATA ANALYSIS}

Changes in LH levels were identified with a modification of a cluster analysis algorithm that identifies clusters of high, intermediate, and low circulating hormone values in which high (low) clusters differ $(p<0.05)$ from neighboring low (high) clusters (Brown et al., 1988; Karsch et al., 1989). Clusters identified by the algorithm were allocated to high and low stages of LH secretion (clusters of intermediate values were divided equally into high and low stages) and compared between groups with respect to timing and synchrony of the onset and end of the high-LH stage.

Some of the ewes exhibited more than one LH rise during the 11-month period of observation, because they were pinealectomized and thus expressed a circannual rhythm of reproductive neuroendocrine activity (e.g., see Figure 2, ewe 6071, below). It was necessary, therefore, to select a specific LH rise in each ewe for the purpose of testing the hypothesis. Because the response to be evaluated was the synchronization of reproductive neuroendocrine induction following infusion of a long-day pattern of melatonin, we selected the onset of the high-LH stage following the date that the infusion was terminated in the melatonintreated ewes, and the start of the high-LH stage beginning closest to this date in the noninfused controls. Differences in time of the LH rises and falls were evaluated by comparing calendar dates of the start and end of the high-LH stage, using the Mann-Whitney $U$ test (Zar, 1984). 


\section{REPRODUCTIVE STATE AND PHOTOPERIODIC RESPONSE}

Differences in synchrony were analyzed by comparing within-group variability, using the Levene test for the homogeneity of variance (Kotz and Johnson, 1982). Values were considered significantly different if $p<0.05$.

\section{RESULTS}

Representative patterns of serum LH are shown in Figure 2 for ewes infused with melatonin and in Figure 3 for noninfused controls. Figure 4 summarizes the timing of the high- and low-LH stages in each sheep as identified by the cluster analysis algorithm. As seen in Figure 2, the long-day pattern of melatonin had two types of effects. The first effect was a suppression of LH during the infusion in ewes exhibiting high levels when treatment was begun (e.g., Fig. 2, ewe 6059). The second effect was synchronization of an LH rise after the infusion ended. This second effect was the one we evaluated, because recent evidence suggests that synchronization by long days is important to timing the annual reproductive cycle of the ewe (Malpaux et al., 1989; Wayne et al., 1990; Woodfill et al., 1991).

The LH pattern of all ewes following the long-day infusion was the same. Regardless of reproductive state prior to treatment, all 12 ewes showed an LH rise within 2 months after the infusion ended (Figs. 2, 4). Onset of this high-LH stage was synchronous among
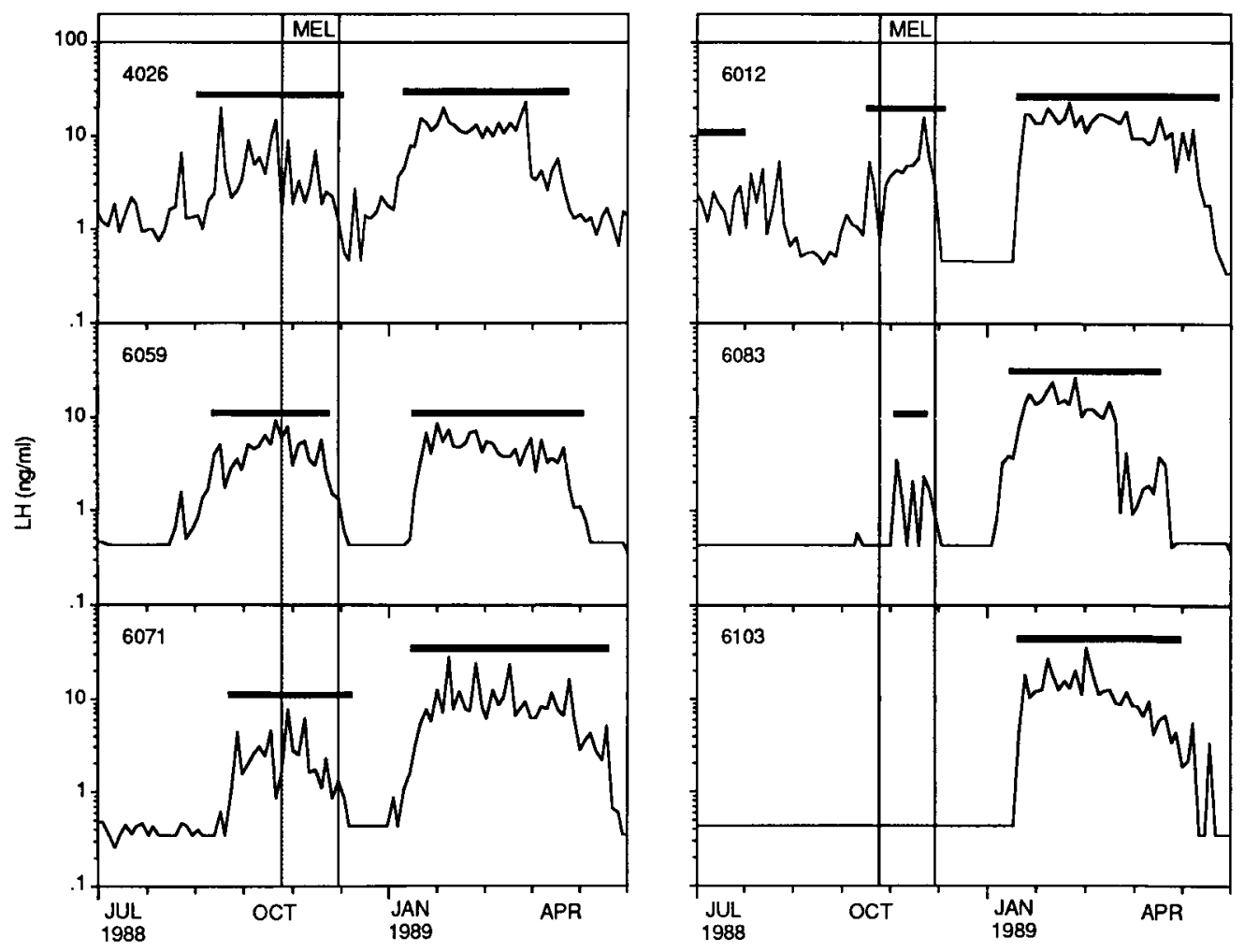

FIGURE 2. Representative serum LH patterns (on logarithmic scale) in pinealectomized ewes infused with a long-day pattern of melatonin (MEL, shading). Horizontal black lines represent high-LH stages that differ significantly from neighboring low-LH stages $(p<0.05$; see "Materials and Methods"). Animal identification number is given in upper left of each panel. 


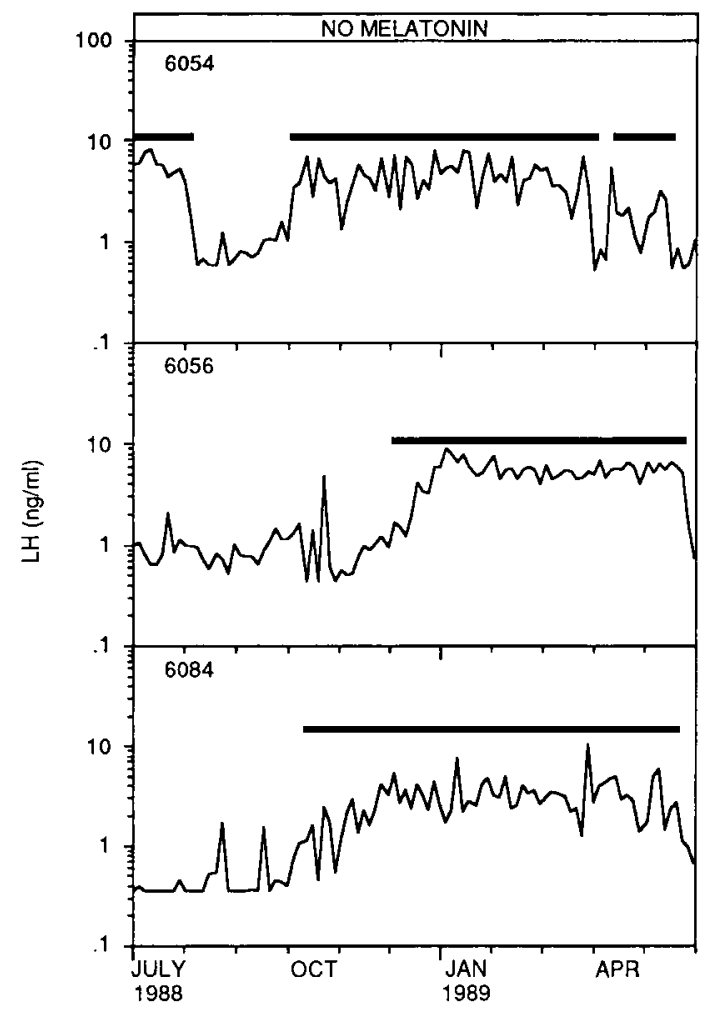

FIGURE 3. Representative serum LH patterns in pinealectomized control ewes not infused with melatonin. For further details, see Figure 2.

ewes, occurring $45 \pm 3$ days after the last day of treatment. LH remained elevated for $108 \pm$ 7 days (mean $\pm S E M$ ) and then fell back to baseline. Each of the noninfused controls exhibited at least one shift between high and low stages of LH secretion.

A difference between the control and infused groups was observed with respect to both date and synchrony of the high-LH stage (Table 1). With regard to synchrony, which is reflected in the standard deviation of group means, the variability in timing of the reproductive transitions was significantly less in melatonin-infused ewes than in the noninfused controls for both onset $(p<0.01)$ and end $(p<0.05)$ of the high-LH stage. With regard to calendar date, the onset of the high-LH stage also differed $(p<0.05)$ between the melatonin-infused and control groups, although no difference was observed in the date the high stage ended (Table 1). Furthermore, the timing of the high-LH stage in melatonin-infused ewes was shifted by some 3-4 months compared to that observed in pineal-intact ewes of the same flock maintained outdoors (Table 1), thus verifying a treatment effect.

\section{DISCUSSION}

In this study, we tested the hypothesis that the neuroendocrine response to a long-day pattern of melatonin depends upon the seasonal reproductive condition of the ewe. For this purpose, we employed an animal model in which the influence of reproductive state could be evaluated 
REPRODUCTIVE STATE AND PHOTOPERIODIC RESPONSE
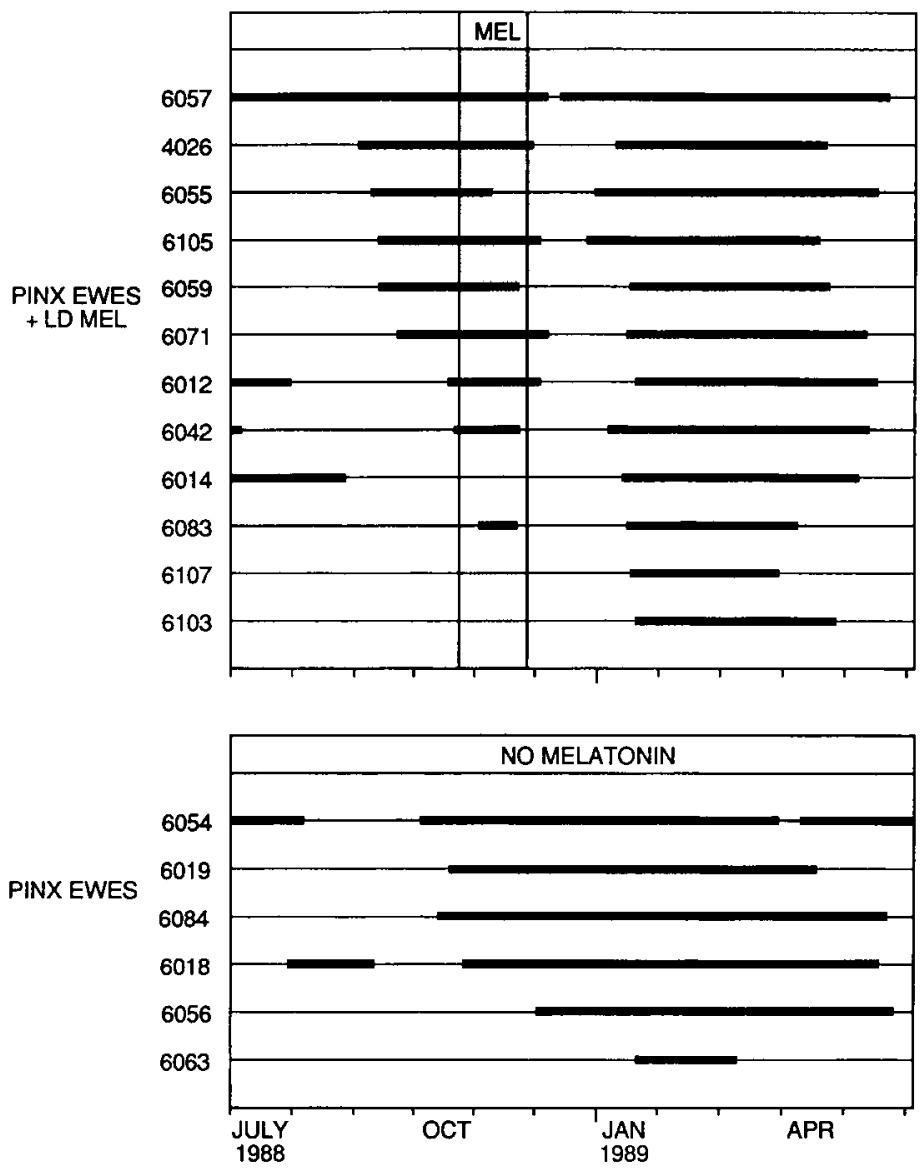

FIGURE 4. Summary of timing of stages of high LH (thick horizontal bars) and low LH (thin horizontal lines) in each pinealectomized ewe treated with a long-day pattern of melatonin (PINX EWES + LD MEL) and each pinealectomized ewe not treated with melatonin (PINX EWES). Hormone values in high-LH and low-LH stages differed significantly $(p<0.05)$ as identified by a cluster analysis algorithm (see "Materials and Methods"). Shaded area represents time of melatonin infusion. Animal identification numbers are given on the left.

TABLE 1. Dates of Onset and End of the High-LH Stage in Ovariectomized Ewes Treated with Estradiol Implant

\begin{tabular}{lrll}
\hline & $n$ & \multicolumn{1}{c}{ Onset $^{a}$} & \multicolumn{1}{c}{ End $^{a}$} \\
\hline Pinealectomized + melatonin & 12 & Jan. $9^{*} \pm 11^{* *}$ & Apr. $30 \pm 17^{*}$ \\
Pinealectomized noninfused & 6 & Nov. $8 \pm 44$ & Apr. $25 \pm 32$ \\
Pineal-intact $^{b}$ & 5 & Sept. $9 \pm 11$ & Jan. $30 \pm 7$ \\
\hline
\end{tabular}

${ }^{a}$ Values are mean \pm standard deviation in days.

${ }^{b}$ Values for pineal-intact ewes over a 5-year period (1983-1988) in same flock as that reported by Karsch et al. (1989). No statistical comparison made with other groups.

$* p \leqslant 0.05$ vs. noninfused control.

$* * p \leqslant 0.01$ vs. noninfused control. 
in the absence of an influence of recent photoperiodic history. The fundamental assumption underlying our study was that the experimental animals had effectively no recent photoperiodic history because they had been pinealectomized for at least 16 months. This assumption would appear valid, because pinealectomy eliminates the reproductive response of ewes to photoperiod (Bittman et al., 1983b) and because our experimental ewes were reproductively desynchronized at the start of the study, suggesting that any effect of photoperiod perceived prior to pinealectomy had dissipated. We submit, therefore, that our experimental approach enabled us to separate possible effects of reproductive state from those of photoperiodic history. Using this approach, we have shown that reproductive state does not affect the ability of infusion of a long-day pattern of melatonin (which mimics a long-day photoperiodic signal) to synchronize reproductive onset. All treated ewes showed a synchronous rise in LH approximately 1-2 months after the infusion ended, followed by a fall in LH some 34 months later. Our findings therefore suggest that this response to the long-day pattern of melatonin did not differ with reproductive state, and thus they do not support the hypothesis that seasonal reproductive condition affects the response to a treatment that mimics a longday photoperiodic signal.

As mentioned in the introduction, interpretation of our earlier studies (Robinson and Karsch, 1987) that examined the influence of photoperiodic history on the reproductive response of the ewe to daylength is complicated by a potential confound of the effects of photoperiodic history and of reproductive state. Our current observations facilitate the interpretation of that study by providing evidence that the response to a given photoperiodic signal may not differ with seasonal reproductive condition. This reinforces the conclusion that photoperiodic history is an important component of the photoperiodic timekeeping process of the ewe. It should be recognized, however, that the applicability of our findings to studies of photoperiodic history is limited because we tested only one specific pattern of melatonin (that mimicking a fixed long-day pattern) and evaluated only one reproductive response, the synchronization of reproductive onset. Our findings, therefore, do not rule out a differential sensitivity to other effects of long days, nor do they exclude an effect of reproductive state on the response to other types of photoperiodic signals, such as short days or a change in daylength.

Finally, it is of interest to consider our results in terms of photoperiodic synchronization of circannual rhythms. Many long-lived species, including sheep, have an annual reproductive rhythm that is synchronized by the annual photoperiodic cycle (Farner, 1985; Gwinner, 1986; Woodfill et al., 1991; Zucker et al., 1991). Such a rhythm was manifested in the present study as asynchronous changes in LH in the pinealectomized controls not infused with melatonin. One way by which photoperiod could achieve synchronization would be for various stages of the rhythm to be differentially responsive to environmental synchronizing cues. For example, a particular photoperiod could advance or delay the rhythm, or could have no effect at all, depending on the rhythm stage. Indeed, there is evidence to suggest that exposure to the same photoperiod can have different effects, depending on the stage of a circannual cycle (birds-Gwinner, 1971, 1973; Gwinner et al., 1988; fish-Duston and Bromage, 1988; sheep-Jackson et al., 1989; Malpaux et al., 1989; squirrels-Lee and Zucker, 1991). All of these studies, however, utilized animals with an intact photoperiodic response system. The results, therefore, are difficult to interpret definitively in terms of a stage-dependent sensitivity to photoperiod, because an influence of photoperiodic history could not be separated from stage of the circannual cycle. 
It should be stressed that our current findings also cannot be interpreted definitively in terms of circannual synchronization, because we did not monitor the long-term effects of melatonin on the endogenous rhythm. Nevertheless, the strategy used in the present study could offer a powerful approach for analyzing the importance of rhythm stage in the synchronization of circannual rhythms. In this regard, it should be possible to test whether stage of the rhythm at the time of a melatonin infusion into pinealectomized ewes influences the ability of a specific melatonin pattern to cause a permanent shift in phase of the underlying rhythm.

In summary, we have used the infusion of melatonin into long-term pinealectomized ewes exhibiting desynchronous circannual reproductive cycles to test the hypothesis that the response to a long-day pattern of melatonin varies with the seasonal reproductive state. Our results do not support this hypothesis, because administration of the long-day pattern of melatonin synchronized reproductive onset, regardless of the point in the seasonal reproductive cycle at which this treatment was given. Our experimental approach enabled us to evaluate the influence of reproductive state in the absence of an influence of photoperiodic history, and it could prove to be a valuable strategy for evaluating the importance of rhythm stage in the synchronization of circannual rhythms.

\section{ACKNOWLEDGMENTS}

We thank Mr. Douglas Doop and Mr. Kirk Van Natter for assistance with the animal experimentation; Ms. Barbara Glover for assistance with radioimmunoassays; Drs. Diarmuid O'Callaghan and Suzanne Moenter for help in designing and conducting the study; Drs. Morton B. Brown and Daniel P. Normolle for help with statistical analysis; Drs. Josephine Arendt and Gordon D. Niswender for supplying assay reagents; and the following core facilities of the Center for the Study of Reproduction (National Institutes of Health Grant No. HD-18258): Sheep Research, Standards and Reagents, Data Analysis, and Administration. A preliminary report of the data presented in this paper has appeared in the abstracts of the Second Meeting of the Society for Research on Biological Rhythms. This research was supported by grants from the National Science Foundation (No. DCB-871099), the National Institutes of Health (Nos. HD-18258, HD-18337), and the Office of the Vice President for Research at the University of Michigan.

\section{REFERENCES}

Bittman, E. L., R. J. Dempsey, and F. J. Karsch (1983a) Pineal melatonin secretion drives the reproductive response to daylength in the ewe. Endocrinology 113: $2276-2283$.

BITTMan, E. L., F. J. KaRSCH, and J. W. Hopkins (1983b) Role of the pineal gland in ovine photoperiodism: Regulation of seasonal breeding and negative feedback effects of estradiol upon luteinizing hormone secretion. Endocrinology 113: 329-336.

Brown, M. B., F. J. Karsch, and B. M. Malpaux (1988) An algorithm to identify changes in hormone patterns. Proc. Symp. Interface Comput. Sci. Stat. 20: 54-59.

Dempsey, R. J., J. Hopkins, E. L. BITTMAN, and G. W. KINDT (1982) Total pinealectomy by an occipital parasagittal approach in sheep. Surg. Neurol. I8: $377-380$.

Duston, J., and N. Bromage (1988) The entrainment and gating of the endogenous circannual rhythm of reproduction in the female rainbow trout (Salmo gairdneri) J. Comp. Physiol. A 164: 259-268.

Ebling, F. J. P., R. I. Wood, J. M. Suttie, T. E. Adel, and D. L. Foster (1989) Prenatal photoperiod influences neonatal prolactin secretion in the sheep. Endocrinology 125: 384-391.

English, J., A. L. Poulton, J. Arendt, and A. M. SYMONS (1986) A comparison of the efficiency of melatonin treatments in advancing oestrus in ewes. J. Reprod. Fertil. 77: 321-327.

FARNER, D. S. (1985) Annual thythms. Ann. Rev. Physiol. 47: 65-82.

Foster, D. L., F. J. P. Ebling, L. E. Claypool, and C. J. I. WoOdFILL (1988) Cessation of long day melatonin rhythms time puberty in a short day breeder. Endocrinology 123: 1636-1641.

GWINNER, E. (1971) A comparative study of circannual 
thythms in warblers. In Biochronometry, M. Menaker, ed., pp. 405-427, National Academy of Sciences, Washington, DC.

GWINNER, E. (1973) Circannual rhythms in birds: Their interaction with circadian rhythms and environmental photoperiod. J. Reprod. Fertil. Suppl. 19: 51-65.

GWINNER, E. (1986) Circannual Rhythms, SpringerVerlag, New York.

Gwinner, E., J. P. DitTami, and H. J. A. Veldhuis (1988) The seasonal development of photoperiodic responsiveness in an equatorial migrant, the garden warbler Sylvia borin. J. Comp. Physiol. A 162: 389 396.

hastings, M. H., A. P. Walker, J. B. Powers, J. Hutchison, E. A. Steel, and J. Herbert (1989) Differential effects of photoperiodic history on the responses of gonadotrophins and prolactin to intermediate daylengths in the male Syrian hamster. $J$. Biol. Rhythms 4: 335-350.

Hauger, R. L., F. J. KarsCh, and D. L. Foster (1977) A new concept for control of the estrous cycle of the ewe based on the temporal relationships between luteinizing hormone, estradiol and progesterone in peripheral serum and evidence that progesterone inhibits tonic LH secretion. Endocrinology 101: 807-817.

Hoffmann, K., and H. lllnerová (1986) Photoperiodic effects in the Djungarian hamster. Neuroendocrinology 43: $317-321$.

HoffManN, K., H. Illnerová, and J. VanĚČé (1986) Change in duration of the nighttime melatonin peak may be a signal driving photoperiodic responses in the Djungarian hamster (Phodopus sungorus). Neurosci. Lett. 67: 68-72.

HoRTON, T. H. (1984) Growth and reproductive development of male Microtus montanus is affected by the prenatal photoperiod. Biol. Reprod. 31: 499-504.

JACKSON, G. L., M. GiBson, and D. KueHL (1988) Photoperiodic disruption of photorefractoriness in the ewe. Biol. Reprod. 38: 127-134.

JACKSON, G. L., H. T. JANSEN, D. E. KueHL, and R. D. SHANKs (1989) Time of the sidereal year affects responsiveness to the phase-resetting effects of photoperiod in the ewe. J. Reprod. Fertil. 85: 221-227.

Karsch, F. J., E. L. BittMan, D. L. Foster, R. L. Goodman, S. J. Legan, and J. E. Robinson (1984) Neuroendocrine basis of seasonal reproduction. Rec. Prog. Horm. Res. 40: 185-232.

KaRsch, F. J., D. J. DieRschKe, R. F. Weick, T. YamaJI, J. HotchKISs, and E. KNOBIL (1973) Positive and negative feedback control by estrogen of luteinizing hormone secretion in the rhesus monkey. Endocrinology 92: 799-804.

KARSCH, F. J., and D. L. Foster (1975) Sexual differentiation of the mechanism controlling the preovulatory discharge of luteinizing hormone in sheep. Endocrinology 97: 373-379.

Karsch, F. J., J. E. Robinson, C. J. I. Woodfill, and M. B. BRown (1989) Circannual cycles of luteinizing hormone and prolactin secretion in ewes during pro- longed exposure to a fixed photoperiod: Evidence for an endogenous reproductive rhythm. Biol. Reprod. 41: $1034-1046$.

KoTZ, S., and N. L. JoHNson, eds. (1982) Encyclopedia of Statistical Sciences, Wiley, New York.

LEE, T. M., and I. ZUCKER (1988) Vole infant development is influenced perinatally by maternal photoperiodic history. Am. J. Physiol. 255: R831-R838.

LEE, T. M., and I. ZUCKER (1991) Suprachiasmatic nucleus and photic entrainment of circannual rhythms in ground squirrels. J. Biol. Rhythms 6: 315-330.

LEGAN, S. J., and F. J. KaRSCH (1979) Neuroendocrine regulation of the estrous cycle and seasonal breeding in the ewe. Biol. Reprod. 20:74-85

LeGAN, S. J., F. J. KARSCH, and D. L. Foster (1977) The endocrine control of seasonal reproductive function in the ewe: A marked change in response to the negative feedback action of estradiol on luteinizing hormone secretion. Endocrinology 101: 818-824.

MalpauX, B., J. E. Robinson, M. B. Brown, and F. J. KARSCH (1987) Reproductive refractoriness of the ewe to inductive photoperiod is not caused by inappropriate secretion of melatonin. Biol. Reprod. 36: $1333-1341$.

MalpauX, B., J. E. Robisnon, N. L. Wayne, and F. J. KARSCH (1989) Regulation of the onset of the breeding season of the ewe: Importance of long days and of an endogenous reproductive rhythm. J. Endocrinology 122: 269-278

Niswender, G. D., A. R. Midgley, and L. E. Reichert (1968) Radioimmunologic studies with murine, bovine, ovine, and porcine luteinizing hormone. In Gonadotropins, E. Rosenberg, ed., pp. 229-306, Geron$\mathrm{X}$, Los Altos, CA.

Niswender, G. D., L. E. Reichert, A. R. Midgley, JR., and A. V. NALBANDOV (1969) Radioimmunoassay for bovine and ovine luteinizing hormone. Endocrinology 84: 1166-1173.

Robinson, J. E., and B. K. Follett (1982) Photoperjodism in Japanese quail: The termination of seasonal breeding by photorefractoriness. Proc. Roy. Soc. Lond. B. 215: 95-116.

RobinsON, J. E., and F. J. KaRSCH (1987) Photoperiodic history and a changing melatonin pattern can determine the neuroendocrine response of the ewe to daylength. J. Reprod. Fertil, 80: 159-165.

Roche, J. F., and P. J. Dziuk (1969) A technique for pinealectomy of the ewe. Am. J. Vet. Res. 30: $2031-2035$

Wayne, N. L., B. M. Malpaux, and F. J. Karsch (1988) How does melatonin code for day length in the ewe: Duration of nocturnal melatonin release or coincidence of melatonin with a light-entrained sensitive period? Biol. Reprod. 39: 66-75.

Wayne, N. L., B. M. MalpauX, and F. J. Karsch (1990) Photoperiodic requirements for timing onset and duration of the breeding season in the ewe. $J$. Comp. Physiol. 166: 835-842.

WoOdFLL, C. J. I. (1990) Photoperiodic Synchronization 
REPRODUCTIVE STATE AND PHOTOPERIODIC RESPONSE

of the Annual Reproductive Rhythm of the Ewe, $\mathrm{PhD}$ dissertation, University of Michigan.

Woodfill, C. J. 1., J. E. Robinson, B. MalpauX, and F. J. KARSCH (1991) Synchronization of the circannual reproductive rhythm of the ewe by discrete photoperiodic signals. Biol. Reprod. 45: 110-121.

ZAR, J. H. (1984) Biostatistical Analysis, Prentice-Hall,
Englewood Cliffs, NJ.

ZuCKER, I., T. M. LEE, and J. DARK (1991) The suprachiasmatic nucleus and annual rhythms of mammals. In Suprachiasmatic Nucleus: The Mind's Clock, D. Klein, S. Reppert, and R. Moore, eds., pp. 246259, Oxford University Press, New York. 